\title{
Meta
}

Journal des traducteurs

Translators' Journal

\section{Traducción y represión. El catalán durante la primera etapa de la dictadura de Franco (1939-1961)}

\section{Montserrat Bacardí}

Volume 60, numéro 2, août 2015

$60^{\mathrm{e}}$ anniversaire. Les horizons de la traduction : retour vers le futur $60^{\text {th }}$ Anniversary. Translation's Horizons: Back to the Future

60mo aniversario. Los horizontes de la traducción: regreso al futuro

URI : https://id.erudit.org/iderudit/1032863ar

DOI : https://doi.org/10.7202/1032863ar

Aller au sommaire du numéro

Éditeur(s)

Les Presses de l’Université de Montréal

ISSN

0026-0452 (imprimé)

1492-1421 (numérique)

Découvrir la revue

Citer ce document

Bacardí, M. (2015). Traducción y represión. El catalán durante la primera etapa de la dictadura de Franco (1939-1961). Meta, 60(2), 312-312.

https://doi.org/10.7202/1032863ar d'utilisation que vous pouvez consulter en ligne. 


\title{
Traducción y represión. El catalán durante la primera etapa de la dictadura de Franco (1939-1961)
}

\author{
MontSERRAT BACARdí \\ Universitat Autònoma de Barcelona, Barcelona, España \\ Montserrat.Bacardi@uab.cat
}

Como medida de control editorial y político, muchos regímenes totalitarios han fijado su atención en la traducción. Esta ha sido estrechamente vigilada o directamente prohibida por doquier y en todos los tiempos, en tanto que se ha considerado una de las armas más eficaces de modernización de culturas. Este trabajo presenta un caso ciertamente singular en la Europa contemporánea: el de la traducción catalana bajo la dictadura militar de Francisco Franco (1939-1975). Durante más de dos décadas, el régimen practicó una doble censura, ideológica y lingüística. Es decir, al tiempo que no se podía publicar un libro que cuestionara la religión, la moral o la política impuestas en cualquiera de las lenguas del Estado (castellano, catalán, gallego y vasco), hasta el año 1962 fueron especialmente perseguidas las traducciones a las "otras" lenguas españolas que no fueran la castellana. A partir de 1962, con un cambio legislativo que dejaba de penalizar por defecto las lenguas "minoritarias" o "minorizadas", la traducción al catalán experimentó una revitalización que, recuperando el tiempo perdido, convirtió al catalán en una de las lenguas más traductoras de la década de los sesenta (como reflejan estudios estadísticos).

Nuestra atención se centra, sin embargo, en el primer período de la dictadura, los años oscuros y silentes, los de persecución implacable de manifestaciones públicas en la lengua originaria del territorio y, con mayor contumacia, de las traducciones. ¿Cuáles eran los criterios "oficiales" de la censura y la argumentación esgrimida? ¿Cómo se sortearon las prohibiciones? ¿Qué tipo de obras se tradujo? ¿Qué autores? ¿De qué lenguas? ¿Quiénes lo hicieron? ¿Qué empresas editoriales se atrevieron primero a saltarse los controles policiales y después comercializaron los libros? ¿Cuál fue, si existió, su recepción coetánea? Estas no son sino algunas de las muchas preguntas que surgen de entrada y a las que intentamos dar respuesta en esta investigación. Porque, a pesar de todo, los múltiples intentos de acallar la transmisión de voces foráneas por medio de una lengua perseguida no consiguieron su objetivo final: la eliminación de la alteridad $\mathrm{y}$, en última instancia, de la lengua

Montserrat Bacardí, doctora en Filología Hispánica y licenciada en Filología Catalana, es profesora de la Facultad de Traducción e Interpretación de la Universitat Autònoma de Barcelona. Desde 1998 es coordinadora de Quaderns. Revista de Traducció. Ha publicado artículos de historia de la literatura y de la traducción y los libros Alfons Costafreda. La temptació de la poesia (1989), Cent anys de traducció al català (1891-1990). Antologia (1998), Anna Murià. El vici d'escriure (2004), El Quixot en català (2006), Catalans a Buenos Aires. Records de Fivaller Seras (2009), La traducció catalana sota el franquisme (2012) y, con Pilar Godayol, Una impossibilitat possible. Trenta anys de traducció als Països Catalans (1975-2005) (coord.) (2010), Diccionari de la traducció catalana (dir.) (2011, premio Crítica Serra d'Or 2012) y Les traductores i la tradició (2013). 